\title{
Implementasi Algoritma Genetika untuk Menentukan Karakter Green house dengan Teknik Identifikasi
}

\author{
Melania Suweni Muntini* \\ Lab. Bio-Instrumentasi, Fisika-FMIPA, \\ Institut Teknologi Sepuluh Nopember \\ Kampus ITS Sukolilo, Surabaya 61111 \\ Yul Y Nazaruddin \\ Program Studi Fisika Teknik, Institut Teknologi Bandung \\ Jl. Ganesha No.10, Bandung 40132
}

\begin{abstract}
Intisari
Salah satu cara untuk pengkondisian temperatur di dalam suatu green house adalah dengan mengenali perilaku dan karakter perubahan temperaturnya. Pengenalan karakter dapat dilakukan dengan mencari model perubahan temperatur di dalam green house tersebut. Ada berbagai cara untuk melakukan pemodelan, yang diantaranya adalah dengan teknik identifikasi berdasarkan hasil pengukuran masukan-keluarannya. Pada makalah ini disajikan hasil penelitian yaitu pengembangan teknik identifikasi sistem dengan menggunakan algoritma genetik. Algoritma genetik yang dikembangkan dalam penelitian ini menggunakan fungsi fitness yang didasarkan pada residu antara keluaran sistem dan keluaran model. Pengukuran masukan-keluaran dalam penelitian ini dilakukan pada suatu miniatur green house. Dengan memadukan teknik identifikasi dan algoritma genetik, karakter perubahan temperatur dalam green house dapat didekati menggunakan model Auto Regressive Moving Average with Exogenous Input (ARMAX). Hasil yang diperoleh untuk proses pemanasan dan pendinginan dalam green house adalah model dengan struktur ARMAX orde 3. Model tersebut diperoleh dengan nilai fitness terbaik 0,89 untuk proses pemanasan dan 0,98 untuk proses pendinginan.
\end{abstract}

KATA KUNCI: algoritma genetika, ARMAX, pemodelan, green house, sistem identifikasi

\section{PENDAHULUAN}

II. DASAR TEORI

\section{A. Identifikasi Sistem}

Pengaturan temperatur suatu green house dilakukan untuk mengatur keadaan udara agar tetap memenuhi kondisi dan persyaratan tertentu yang telah banyak dilakukan. Salah satu cara agar pengaturan temperatur dapat dilakukan, maka perilaku dan karakter sistem yaitu perubahan dari panas ke dingin dan sebaliknya harus dikenali terlebih dahulu. Salah satu cara untuk mengenali karakter sistem adalah dengan melakukan pemodelan sistem. Untuk keperluan tersebut maka dilakukan pengamatan pada green house tersebut.

Ada beberapa metode yang dapat digunakan untuk melakukan pemodelan, yang diantaranya adalah dengan teknik identifikasi sistem yaitu dengan mencari hubungan antara masukan dan keluaran. Beberapa algoritma dapat diterapkan untuk melakukan teknik identifikasi. Dalam makalah ini disampaikan pengembangan teknik identifikasi dengan menggunakan algoritma genetik. Pemodelan dengan metode ini harus ditentukan terlebih dahulu kandidat model dengan struktur model yang telah ditentukan [1].

${ }^{*}$ E-MAIL: melania@physics.its.ac.id
Dalam melakukan identifikasi sistem ada beberapa cara yang salah satunya adalah melakukan pemodelan dengan model black box. Pada pemodelan dengan cara ini, diperlukan masukan dan keluaran dari sistem. Data yang diambil harus dapat memberikan informasi yang cukup tentang perilaku sistem. Selanjutnya berdasarkan hasil pengukuran dan sifat-sifat sistem yang diamati tersebut dilakukan proses identifikasi yang tujuannya adalah menentukan kandidat-kandidat model. Untuk menentukan kandidat model, struktur dan orde dari model harus diperhatikan. Beberapa struktur model yang memasukkan unsur gangguan (noise) adalah model Auto Regressive with Exogenous Input (ARX) dan Auto Regressive Moving Average with Exogenous Input (ARMAX).

Dalam penelitian ini, agar dalam pemodelan dapat lebih leluasa memperhitungkan suku gangguan (noise) maka di pilih struktur model ARMAX [2], yang dituliskan sebagai

$$
A(q) y(t)=B(q) u(t-n k)+C(q) e(t)
$$

dengan

$$
\begin{aligned}
& A(q)=1+a_{1} q^{-1}+a_{2} q^{-2}+a_{3} q^{-3}+\cdots+a_{n a} q^{-n a} \\
& B(q)=b_{\circ}+b_{1} q^{-1}+b_{2} q^{-2}+b_{3} q^{-3}+\cdots+b_{n b} q^{-n b} \\
& C(q)=1+c_{1} q^{-1}+c_{2} q^{-2}+c_{3} q^{-3}+\cdots+c_{n c} q^{-n c}(2)
\end{aligned}
$$




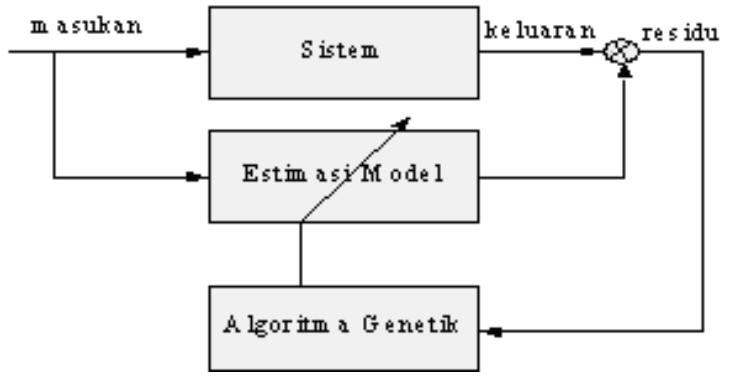

Gambar 1: Skema Identifikasi Sistem dengan Algoritma Genetik

\section{B. Algoritma Genetik}

Secara umum, algoritma genetik bermain di ruang solusi, dan akan mencari solusi terbaik dari ruang solusi tersebut (search space) [3]. Semua calon solusi yang dipilih akan dievaluasi tingkat kebaikannya dengan fungsi tertentu (fitness function) sehingga dapat diketahui calon solusi yang memegang tingkat fitness tertinggi. Beberapa calon solusi terbaik akan dipilih untuk dikawinkan agar dapat menghasilkan solusi baru dengan harapan nilai kebaikannya lebih tinggi dari pada orangtuanya. Juga bisa terjadi mutasi dari sebuah solusi menjadi solusi baru dengan harapan yang sama.[4]

Algoritma genetik diawali dengan dibentuknya himpunan solusi secara random yang disebut populasi. Setiap individu dalam populasi disebut kromosom yang merepresentasikan sebuah solusi. Kromosom-kromosom berkembang melalui iterasi beruntun yang disebut generations. Pada setiap generasi, kromosom dievaluasi dengan menggunakan alat tertentu (fitness function). Untuk menghasilkan generasi berikutnya (keturunan/offspring), kromosom baru dihasilkan dengan dua cara yaitu perkawinan silang antar dua kromosom pada generasi sebelumnya (crossover) atau terjadi mutasi pada sebuah kromosom dari generasi sebelumnya. Generasi baru terbentuk dengan memilih kromosom-kromosom pada generasi berikutnya beserta generasi sebelumnya sesuai dengan nilai fitnessnya, dan membuang beberapa kromosom yang nilai fitnessnya buruk, untuk menjaga agar jumlah anggota populasi konstan. Setelah berjalan beberapa generasi, maka algoritma genetik akan menghasilkan solusi yang mengarah pada solusi terbaik.

\section{Identifikasi dengan Algoritma Genetik}

Teknik identifikasi yang dikembangkan dengan algoritma genetik ini menghasilkan suatu nilai yang digunakan sebagai kriteria untuk menentukan nilai parameter model sistem.
Keluaran dari proses algoritma genetik adalah nilai fitness yang optimum. Prosedur yang dilakukan untuk mengidentifikasi sistem dengan menggunakan algoritma genetik diperlihatkan dalam Gambar 1.

Keuntungan identifikasi dengan menggunakan algoritma genetik adalah selalu ada peluang untuk mendapatkan solusi optimum. Sebelum diuji dengan menggunakan kriteria statistik yang ada, kandidat yang dihasilkan ini telah memenuhi kriteria yang ada dalam algoritma genetik. Dengan melihat nilai fitness yang dihasilkan, maka dapat diperkirakan apakah suatu kandidat model layak untuk dipilih atau tidak [3].

\section{METODE PENELITIAN}

\section{A. Pengambilan Data}

Pengambilan data dilakukan dalam suatu green house yang dibuat dari lembaran kayu multiplex dan teakwood. Pada bagian dalam green house ditempatkan dua kipas DC 12 volt, dua elemen pemanas dengan kapasitas maximal total 25 watt, pada tegangan 12,5 volt, dan sebuah sensor temperatur LM35 DZ. Terhadap udara di dalam green house ini dapat dilakukan dua sistem pengkondisian yaitu sistem pemanasan dan sistem pendinginan udara secara bergantian.

Selama proses pemanasan kedua elemen pemanas yang ada dalam green house berfungsi sebagai aktuator, sedangkan kedua kipas berfungsi untuk meratakan temperatur ke seluruh ruangan. Pada proses pendinginan salah satu kipas berfungsi sebagai aktuator untuk meniupkan udara ke permukaan es, sedang kipas yang lain berfungsi untuk meratakan temperatur. Salah satu elemen pemanas diberi tegangan konstan 12 volt yang berfungsi sebagai beban.

Dalam melakukan identifikasi green house digunakan data masukan keluaran hasil eksperimen sebanyak 250 cacah data. Sebagai masukannya adalah tegangan penggerak aktuator yang berkisar antara 0 sampai 5 volt, sedangan keluarannya adalah temperatur ruangan. Masukan keluaran sistem hasil pengukuran diperlihatkan dalam Gambar 2 dan Gambar 3.

\section{B. Penentuan Kandidat Model}

Untuk mendapatkan kandidat model, maka data masukan dan keluaran akan diidentifikasi dengan menggunakan Toolbox Identifikasi Matlab 6.5. Dari identifikasi tersebut diperoleh nilai parameter $\mathrm{a}=3, \mathrm{~b}=1, \mathrm{c}=2$ dan $\mathrm{k}=1$ untuk proses pemanasan. Kemudian dengan memasukkan nilai dari parameter tersebut maka diperoleh

$$
\begin{gathered}
y(t)\left\{1+a_{1} q^{-1}+a_{2} q^{-2}+a_{3} q^{-3}\right\}=u(t-1)\left\{b_{1}+b_{2} q^{-1}\right\}+e(t)\left\{1+c_{1} q^{-1}+c_{2} q^{-2}\right\} \\
y(t)=-a_{1} y(t-1)-a_{2} y(t-2)-a_{3} y(t-3)+b_{1} u(t-2)+b_{2} u(t-3)+c_{1} e(t)+c_{2} e(t-1)
\end{gathered}
$$




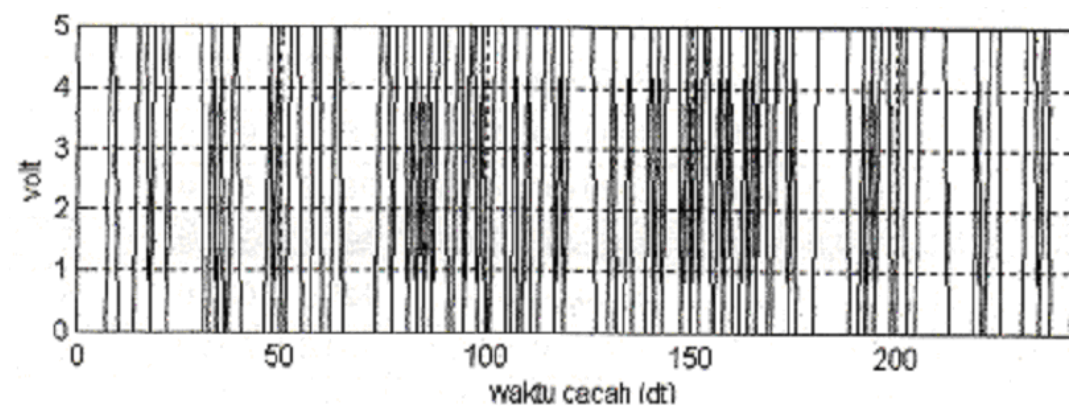

Gambar 2: Masukan Sistem

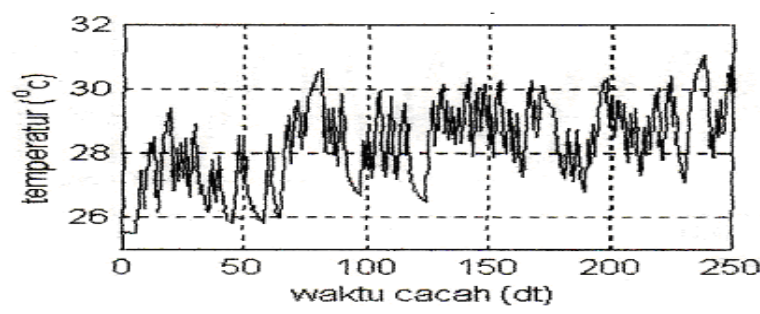

(a)Proses Pemanasan Green house

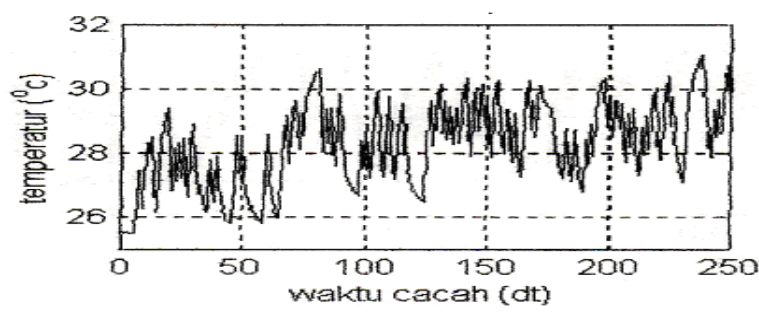

(b)Proses Pendinginan Green house

Gambar 3: Keluaran Sistem

sedangkan untuk proses pendinginan diperoleh kandidat model

$$
\begin{array}{r}
y(t)\left\{1+a_{1} q^{-1}+a_{2} q^{-2}+a_{3} q^{-3}\right\}=u(t)\left\{b_{1}+b_{2} q^{-1}\right\}+e(t)\left\{1+c_{1} q^{-1}+c_{2} q^{-2}\right\} \\
y(t)=-a_{1} y(t-1)-a_{2} y(t-2)-a_{3} y(t-3)+b_{1} u(t-1)+b_{2} u(t-2)+c_{1} e(t)+c_{2} e(t-1)
\end{array}
$$

\section{Implementasi Algoritma Genetik dalam Pemodelan}

Dengan diperolehnya kandidat model maka algoritma genetik dapat diimplementasikan untuk menentukan model terbaik dengan menentukan nilai parameter-parameter a, b dan c. Kromosom yang akan diproses dengan algoritma genetik adalah $\left[\begin{array}{lll}a_{1} & a_{2} & a_{3}\end{array}\right] ;\left[b_{1} b_{2}\right] ;\left[\begin{array}{lll}c_{2} & c_{3}\end{array}\right]$ dan $\left[\begin{array}{lll}a_{1} & a_{2} & a_{3}\end{array}\right]$; $\left[\begin{array}{ll}b_{1} & b_{2}\end{array}\right] ;\left[\begin{array}{ll}c_{2} & c_{3}\end{array}\right]$ masing-masing untuk proses pemanasan dan pendinginan. Dalam identifikasi dengan algoritma genetik ini digunakan probabilitas crossover 0,9 ; probabilitas mutasi adalah 0,1 dan populasi 20 .

Fungsi fitness yang digunakan dalam identifikasi dengan algoritma genetik ini didasarkan pada residu antara keluaran sistem dan model yang dapat dinyatakan dalam persamaan

$$
f=\frac{1}{1+E}
$$

dengan

$$
E=\frac{\sqrt{\sum_{t=1}^{n} e(i)^{2}}}{n}
$$

dengan $\mathrm{n}$ adalah cacah data dan e(i) adalah residual antara keluaran sistem dan model.

\section{HASIL DAN DISKUSI}

Algoritma yang digunakan untuk identifiasi dalam penelitian ini telah diujicoba dengan menggunakan struktur ARMAX orde 2 dan orde 3 , dengan menggunakan data simulasi. Hasil pengujian menunjukkan bahwa nilai fitness mendekati konvergen sebelum generasi ke 40 untuk orde 2 dan generasi ke 60 untuk orde 3. Dari hasil ini menunjukkan bahwa algoritma yang dikembangkan dapat diimplementasikan dalam sistem idenfikasi untuk menentukan model berdasarkan hubungan masukan-keluaran sistem.

\section{A. Pemilihan Kandidat Model}

Kandidat model pada proses pemanasan dan pendinginan green house adalah struktur ARMAX orde 3 seperti pada Pers.(4) dan Pers.(5). Dari proses algoritma genetik dengan generasi maximum 60 telah diperoleh kandidat model terbaik. 
TABEL I: Kandidat Model Pemanasan Green house

\begin{tabular}{lccccccc}
\hline $\begin{array}{l}\text { Nilai } \\
\text { fitness }\end{array}$ & $\mathrm{a}_{1}$ & $\mathrm{a}_{2}$ & $\mathrm{a}_{3}$ & $\mathrm{~b}_{1}$ & $\mathrm{~b}_{2}$ & $\mathrm{c}_{1}$ & $\mathrm{c}_{2}$ \\
\hline & & & & & & & \\
0,755 & 1,310 & $-0,7909$ & 0,4154 & 0,2020 & $-0,328$ & 0,3898 & 0,4066 \\
0,886 & 0,785 & $-0,032$ & 0,2290 & 0,3466 & $-0,107$ & $-0,247$ & 0,4599 \\
0,780 & 0,784 & 0,2025 & $-0,0041$ & 0,2112 & $-0,007$ & $-0,1613$ & 0,1272 \\
\hline \hline
\end{tabular}

TABEL II: Kandidat Model Pendinginan Green house

\begin{tabular}{llllllll}
\hline \hline Nilai & & & & & & & \\
fitness & $\mathrm{a}_{1}$ & $\mathrm{a}_{2}$ & $\mathrm{a}_{3}$ & $\mathrm{~b}_{1}$ & $\mathrm{~b}_{2}$ & $\mathrm{c}_{1}$ & $\mathrm{c}_{2}$ \\
\hline
\end{tabular}

$\begin{array}{llllllll}0,9765 & 0,1343 & 0,4479 & 0,4303 & -0,0567 & -0,0431 & 0,9440 & 0,5341\end{array}$

$\begin{array}{lllllllll}0,9663 & -0,2004 & 0,2802 & 0,9310 & -0,0757 & -0,0141 & -0,2388 & -0,564\end{array}$

$\begin{array}{lllllllll}0,965 & 0,8338 & 0,0297 & 0,1402 & -0,0490 & -0,0160 & -0,0375 & 0,1262\end{array}$

Kandidat model untuk proses pemanasan dan pendinginan dari greenhouse secara berturut-turut disajikan dalam Tabel 1 dan Tabel 2.
Pada proses pemanasan, dipilih model dengan nilai fitness 0,886 dengan nilai parameter seperti disajikan dalam Tabel 1. Sehingga persamaan model yang dipilih untuk proses pemanasan green house adalah seperti ditunjukkan Pers.9. Sedang pada proses pendinginan, dari kandidat yang ada dipilih model dengan nilai fitness 0,9765 dengan nilai parameter seperti disajikan dalam Tabel 2. Persamaan model yang diperoleh untuk proses pendinginan green house adalah seperti ditunjukkan Pers. 10.

TABEL III: Nilai Statistik Validasi Model Karakteristik Greenhouse

\begin{tabular}{lcc}
\hline \hline & \multicolumn{2}{c}{ Sistem Greenhouse } \\
& Proses Pemanasan Proses Pendinginan \\
\hline Fitness & 0,8861 & 0,9765 \\
Varian & 0,1240 & 0,0239 \\
Tee & 0,0111 & 0,786 \\
Tue & 0,0106 & 2,1006 \\
\hline \hline
\end{tabular}

$$
\begin{array}{r}
y(t)=-0,785 y(t-1)+0,032 y(t-2)+0,229 y(t-3)-0,347 u(t-2)+0,107 u(t-3)+ \\
2,47 e(t)-0,46 e(t-1) \\
y(t)=-0,1343 y(t-1)-0,4479 y(t-2)-0,4303 y(t-3)+0,0567 u(t-2)+0,0431 u(t-3)- \\
0,944 e(t)-0,5341 e(t-1)
\end{array}
$$

Perbandingan antara keluaran sistem dan hasil identifikasi untuk proses pemanasan dan pendinginan secara berturutturut disajikan dalam Gambar 4.a dan Gambar 4.b. Sedangkan selisih antara keluaran sistem dan hasil identifikasi untuk proses pemanasan dan pendingan secara berturut-turut disajikan dalam Gambar 5.a dan Gambar 5.b. Dalam identifikasi sistem dengan algoritma genetik ini pemilihan generasi aksimum 60 karena dalam kenyataannya fungsi fitness sudah konvergen mulai generasi ke 20. Dari Gambar 5.a dan Gambar 5.b menunjukkan bahwa kisaran selisih pada proses pemanasan disekitar nilai 0 lebih besar dibanding pada proses pendinginan. Dalam algoritma genetik hal ini ditandai juga dengan kisaran nilai fitness pada proses pendinginan yang lebih baik dibanding pada proses pemanasan. Nilai fitness terbaik untuk proses pemanasan adalah 0,886 sedangkan untuk proses pendinginan adalah 0,975 .

\section{B. Validasi Model}

Validasi model dilakukan dengan mencari nilai statistik dari model yang diperoleh yaitu fungsi korelasi dan korelasi silang residual antara residu dan masukan dengan tingkat kepercayaan $95 \%$. Hasil validasi proses pemanasan dan pendinginan disajikan dalam Tabel 3.

Dari Pers.(7) dan Pers.(8) serta hasil fitness mendekati satu menunjukkan bahwa residu antara hasil pengukuran dan model sangat kecil. Validasi model juga dilakukan secara visual dari Gambar 5. Gambar 5 menunjukkan keterhimpitan antara keluaran model dan sistem yang tinggi menunjukkan bahwa keluaran model dapat mengikuti keluaran sistem.

\section{SIMPULAN}

Dari penelitian ini dapat disimpulan bahwa proses pemanasan dan pendinginan dalam green house dapat didekati dengan struktur ARMAX orde 3. Model tersebut diperoleh dengan nilai fitness terbaik 0,89 dan 0,98 untuk proses pemanasan dan pendinginan dengan tingkat kepercayaan $95 \%$. 


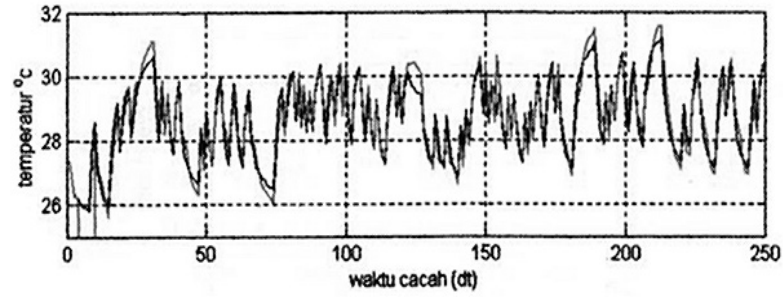

(a)Proses Pemanasan Green house

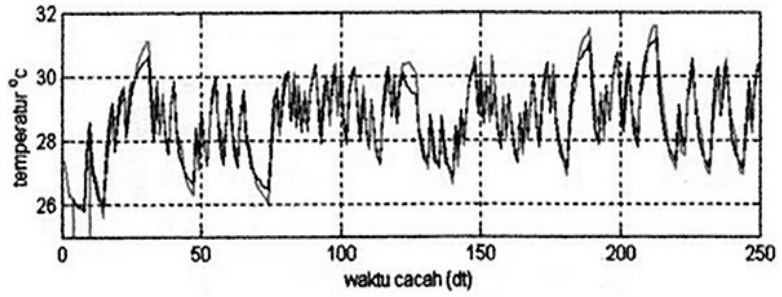

(b)Proses Pendinginan Green house

Gambar 4: Perbandingan keluaran Sistem dan hasil identifikasi

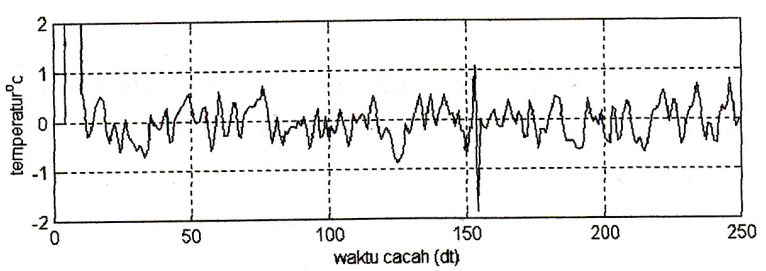

(a)Proses Pemanasan Green house

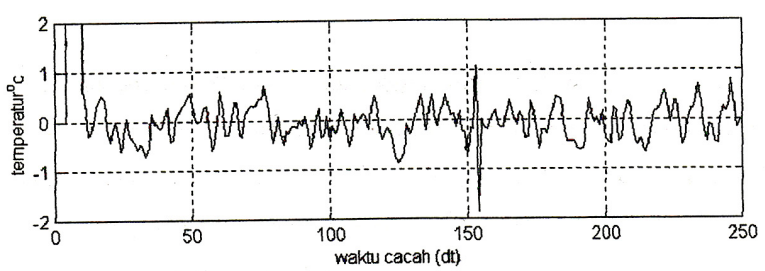

(b)Proses Pendinginan Green house

Gambar 5: Selisih antara Keluaran Sistem dan Hasil Identifikasi

[1] Johansson, Rolf, System Modeling and Identification (Prentice Hall, New York, 1993).

[2] Muntini,S.M, Pemodelan dan Penentuan Orde Model dengan menggunakan Teknik Identifikasi, Thesis, Institut Teknologi Bandung, 2000.

[3] Muntini,S.M and Nazaruddin, Y.Y., Identification of Vehicle Sus- pension Using Genetic Algorithm Technique, Proc. of Indonesia Germany Conference (IGC), Bandung, 2001.

[4] Mitsuo Gen \& Runwei Cheng, Genetic Algorithms \& Engineering Design (John Wiley and Son, 1997). 